\title{
FEBO APOLO NA TRAMA ÉPICA DE MEMORIAL DA INFANCIA DE CHRISTO E TRIUMPHO DO DIVINO AMOR (1639) DE SOROR MARIA DE MESQUITA PIMENTEL
}

\author{
Fabio Mario da Silva* \\ Universidade de São Paulo
}

\begin{abstract}
Resumo: Este artigo foca a maneira como é representada a figura de Apolo na epopeia religiosa de Soror Maria de Mesquita Pimentel (1581-1661), escritora professa do Mosteiro de São Bento de Cástris, na cidade de Évora, e que se tornou a primeira mulher a publicar em língua portuguesa um épico intitulado Memorial da Infância de Cristo e Triunfo do divino Amor (1639), texto de suma importância para se entender o género épico na história da literatura portuguesa e, consequentemente, o uso pelas mulheres da mitologia grega, mesmo em texto produzidos em espaços conventuais. Para isto faremos uma revista em torno do que os críticos dizem a respeito do deus Apolo, enfoque principal da nossa análise, e quais as apropriações que a escritora-monja dá a este mito no seu texto, visto que ele figura com bastante frequência, mais do que outros deuses mitológicos, com a nítida intenção de demonstrar a pluralidade simbólica desta divindade ao serviço do que é benévolo e cristão. Palavras-chave: Apolo. Mitologia. Epopeia religiosa. Soror Maria de Mesquita Pimentel.
\end{abstract}

«Apollon a été le symbole de l'esprit dominant la matière» Yves Bonnefoy (1981, p. 50)

\section{Introdução}

O Memorial da Infância de Christo e Triumpho do divino Amor (1639), primeira epopeia escrita e publicada em língua portuguesa por uma mulher, apesar de ser uma obra de

\section{cc) (i) $\odot$}

EY NC ND Esta obra está licenciada sob uma Licença Creative Commons.

\footnotetext{
* Pós-doutorando em Literatura Portuguesa pela Universidade de São Paulo, com apoio financeiro da FAPESP (Fundação de Amparo à Pesquisa do Estado de São Paulo), doutor e mestre em Literatura pela Universidade de Évora, como bolseiro da FCT. É Membro colaborador do grupo do CEL (Centro de Estudos em Letras da Universidade de Évora) e do CEC (Centro de Estudos Clássicos da Universidade de Lisboa). Também faz parte, como membro integrado, do CLEPUL (Centro de Literaturas e Cultura Lusófona e Europeia) da Faculdade de Letras da Universidade de Lisboa. Já lecionou, na Universidade de Varsóvia (Polônia), como Professor Convidado, as disciplinas de Literatura Brasileira, Portuguesa e Africana em Língua Portuguesa. Atualmente dirige, em conjunto com a professora Cláudia Pazos Alonso, a edição anotada das Obras completas de Florbela Espanca pela Editora Estampa. Tem publicado a obra Da metacrítica à psicanálise: a angústia do "eu" lírico na poesia de Florbela Espanca, João Pessoa, Ideia, 2009. E-mail: famamario@gmail.com.
} 
temática religiosa cumpre alguns requisitos obrigatórios daquele tipo de texto recorrendo, por exemplo, à mitologia greco-romana como componente de construção da trama narrativa ${ }^{1}$. A figura de Apolo é o deus mitológico mais valorizado e evocado nesta obra. Se na Ilíada de Homero ele não se torna o deus mais referenciado da narrativa ${ }^{2}$, apesar de ocupar um espaço privilegiado na acção desta trama - no combate entre os aqueus, seus protegidos, e os troianos - visto dar-se grande destaque a Atena ${ }^{3}$ e a Zeus ${ }^{4}$, a sua imagem é de suma importância na constituição das características narrativas mais marcantes.

Também na obra de Soror Pimentel Apolo ocupa um espaço de prestígio: é o deus mais referido e invocado, mais do que Palas Atena ${ }^{5}$, Mercúrio ${ }^{6}$ ou Diana ${ }^{7}$. O que nos propomos é, precisamente, analisar a função que a autora atribui à figura de Apolo e, consequentemente, como esse deus é revistado sob o olhar de uma monja-escritora. Para tanto, precisamos aludir às ideias que rodeiam este mito.

\section{Desenvolvimento}

A figura de Apolo é, dentre as deidades greco-romanas, uma das mais vivas e disseminadas o que fez com que este deus contivesse em si mesmo uma múltipla complexidade de personalidades. Apolo tanto pode ser visto como protetor de caçadores e caçador, deus da profecia, arqueiro, líder das musas, provedor da medicina, deus da saúde, amante, deus da poesia e ligado à música, deus dos homens jovens e da beleza, possuindo nomes como Febo, Délio, Anfrísio, Amador de Clíve, senhor de Delos, Tímbrio/Timbreu

\footnotetext{
${ }^{1}$ A obra é dividida em 10 cantos: Canto I, 97 est.; Canto II, 91 est.; Canto III, 104 est.; Canto IV, 83 est.; Canto V, 85 est.; Canto VI 106 est.; Canto VII 85 est.; Canto VIII, 78 est.; Canto IX, 97 est.; Canto X 81 est.) perfazendo a obra um total de 907 versos com dez sílabas métricas, tratando-se, em sua maioria, de versos heróicos.

${ }^{2}$ De certa forma, Apolo pode ser visto como um dos protagonistas da trama da Ilíada já que ele teve o seu sacerdote menosprezado pelo chefe dos Aqueus, Agaménon, que desposou e raptou, após a conquista do território apolíneo sagrado, a filha do sacerdote de Apolo, Crises, de nome Criseida.

${ }^{3}$ Palas Atenas é principalmente referenciada, e com grande destaque, em A Odisseia.

${ }^{4} \mathrm{Na}$ obra, Pimentel não cita Zeus, sobressaindo, ao invés, a figura do Deus cristão.

${ }^{5}$ Minerva, o nome romano desta mesma deusa, é referenciada na abertura invocativa, no canto I, ressurgindo no canto VIII, no qual, numa tentativa de valorização da figura cristã em relação à pagã, se refere que a toalha usada para enxugar o menino Jesus era muito mais engenhosa do que a tecida por Palas: «Qual o crystal \& alfojar que manava/ De sua bella fronte sobre as rosas,/ Com mais finas toalhas lhe limpava,/ Que as que Pallas ficou industriosos» (Canto VIII, est. 60, fl. 122v.).

${ }^{6}$ Marte é invocado na cena da matança dos primogénitos em Belém, visto que Herodes, incitado por fantasmas, dá ordem para esse genocídio infantil. As mães, ao verem seus filhos sendo mortos cruelmente exclamam: «Com minino às paredes atirando,/ Se lhe abria a cabeça, \& as mâis vião/ Os miolos que d'ella the sahião» (Canto VIII, est. 15, fl. 115), recorrendo ao deus da guerra por misericórdia: «Outra toda chorosa \& esmorecida/ Pede misericordia ao fero Marte,/ E elle executivo nos rigores/ Co ferro despedaça as tenras flores» (Canto VIII, est. 16, fl. 115).

${ }^{7}$ Diana comparece, por exemplo, como meio comparativo com uma grande árvore formosa quando a família sagrada, fugindo de Belém por causa do aviso de um anjo em relação ao infanticídio geral ordenado por Herodes, chega à cidade egípcia de Heliópolis: «Competindo arrogante, alegre, \& ufana/ Na alteza \& fermosura com Diana» (Canto VII, est. 82, fl. 111v.).
}

Anu. Lit., Florianópolis, v. 20, n. 1, p. 201-212, 2015. ISSNe 2175-7917 
(epíteto em Troia), etc. Tais epítetos dão-nos uma amostra da sua constituição problemática, como assim bem analisou Fritz Graf: «Apollo was always complex and contradictory, in the myths and cults of the Greek and Roman World as much as in his lates reception. As each epoch produced its sculptural image of the god» (GRAF, 2009, p. 79). Contudo, como revela Abel Pena, apesar das suas anamorfoses e reescritas, ${ }^{8}$ o mito de Apolo mantém-se estável na sua morfologia e sistema de base, constituindo-se de elementos semânticos e iconográficos que lhe dão uma identidade única, bem diferenciada de outros deuses:

Entidade solar, deus da razão, do belo e da euforia cósmica, Apolo, "o mais grego dos deuses", é menos complexo que Baco ou Vénus, mas não menos intrigante. Talvez por isso, quase nenhum dos episódios do mito apolíneo escape à interpretação dos poetas, cujo objectivo, sublinhe-se, é mais poiético do que propriamente narrativo. (PENA, 2008, p. 44-45)

Esse ornamento narrativo, numa epopeia religiosa como a de Pimentel, com a utilização exacerbada da figura de Apolo $^{9}$, se faz presente como forma de pré-requisito para compor o poético no épico, tal e qual em epopeias clássicas. Mas os deuses resgatados já não desencadeiam as problemáticas da trama, pois comparecem, no caso do texto da escritoramonja, como forma comparativa ou ilustrativa. Entretanto, é preciso frisar que o uso desta figura mitológica é algo recorrente na literatura portuguesa e espanhola dos séculos XVI a $\mathrm{XVII}^{10}$, tendo sido apresentado como, por exemplo, apontaram Vanda Anastácio e Inês de Ornellas e Castro, em obras portuguesas setecentistas, como «juiz das causas humanas» (ANASTÁCIO; CASTRO, 2010, p. 115).

Por seu turno, Abel Pena revela que Apolo, em conjunto com as musas, são as duas principais fontes de referência da poesia portuguesa quinhentista, «quando se fala em exaltar a arte, a condição poética e o sentido de existência» (PENA, 2008, p. 37). É exatamente esse um dos sentidos da presença deste deus na épica de Pimentel: como assistente que enobrece e inspirando o cantar da existência humana, a vinda do salvador da humanidade, o menino

\footnotetext{
${ }^{8} \mathrm{O}$ mesmo estudioso releva, no Dicionário de Luís de Camões, que diante das versões gregas, latinas e pósclássicas sobre o mito encontramos as seguintes versões: «nos mais antigos textos literários gregos, Apolo é conhecido por vários epítetos alusivos à sua natureza ambigua: é Klobos, "deus que acerta ao longe”, alexíkakos, "deus que afasta o mal"; lóxios, "obliquo"; sauroctónos, "matador de serpente"; Febo, nome próprio e epíteto latino mais difundido, encontra-se relacionado com phóbos (terror) e phô̂bos (brilhante, solar)» (PENA, $2010, \mathrm{p}$. 31).

${ }^{9}$ Os poetas cantavam Apolo como o deus da música, recorrendo a ele como forma de inspiração na busca pela harmonia e sonoridade dos textos versificatórios, tal como explicita Yves Bonnefoy: «Et lorsque les poètes tardifs imaginent le dieu maintenant l'univers dans l'harmonie de son mouvement, grâce aux accents de sa lyre, avec pour archet les rayons du soleil, ils ne font que transposer sur le plan cosmique l'image d'une société "bien tempérée", qu'avaient construite avant eux les Pythagoriciens, sous le patronage de la divinité qui faít danser les mondes, comme elle faít danser les diuex» (BONNEFOY, 1981, p. 54).

${ }^{10}$ A presença deste deus é tão forte na literatura portuguesa que o poeta maior, Camões, o cita, como constatou Abel Pena, mais que qualquer outro, até mesmo Vénus, assumindo assim centralidade e destaque tanto na lírica quanto na épica camoniana (PENA, 2010, p. 32-33).
} 
Jesus. É importante observarmos que a autora, por mostrar um vasto conhecimento sobre mitologia em sua obra, resgata visões poéticas tradicionais deste mito, mas o ilumina com aspectos, com funções e com valores que se adequam à sua leitura enquanto religiosa e mulher. Por isso, há de se notar, logo no primeiro canto, a invocação de Apolo como figura pastoril, santa, e como um exímio cantor, qualidades que lhe inspiram a função poética do épico:

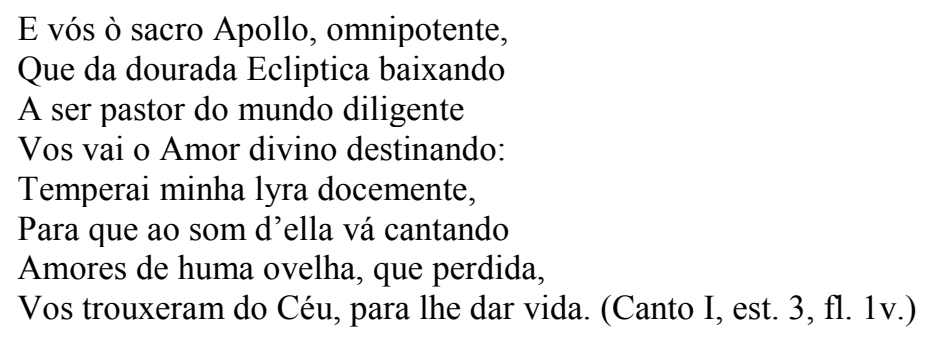

Esta mesma imagem de divindade musical, com um doce timbre ${ }^{11}$, é resgatada pela autora no Canto VI, que narra a procura dos Reis Magos para presentear ${ }^{12}$ o menino Jesus, já que Apolo seria o guia do canto épico, tornando a voz da narradora divina:

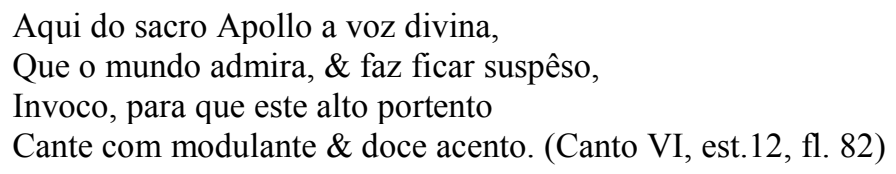

Contudo, Apolo reaparece ainda no primeiro canto mostrando o seu poder de luz, mas, o Deus Cristão, na sua suma sapiência, é mais rápido e portentoso que Apolo, criando os elementos naturais, o dia e a noite, como prova de seu divino amor, provendo ao mundo os animais e a raça humana ${ }^{13}$ :

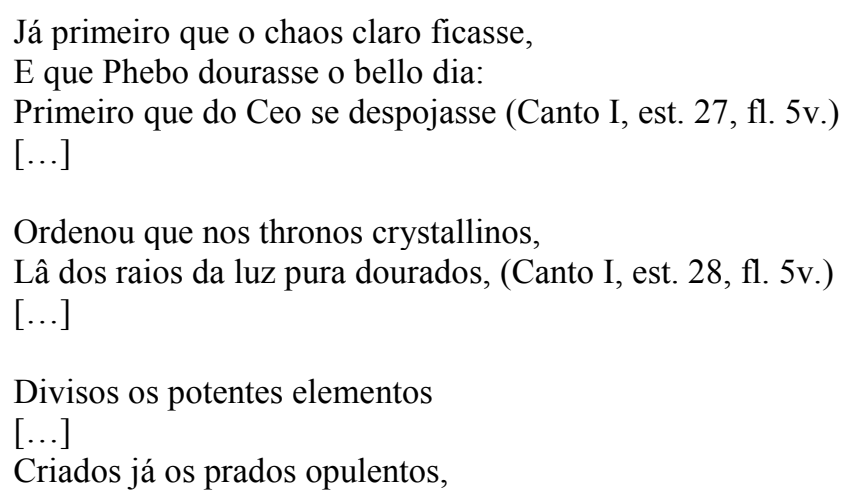

\footnotetext{
${ }^{11}$ Segundo Isabel Morujão esse timbre doce seria indicativo de uma diferença substancial face ao estilo nobre e elevado que «costumam ser solicitado às Musas nos inícios dos poemas épicos» (MORUJÃO, 2013, p. 163).

12 Lembremo-nos aqui que, tal como o menino Jesus, Apolo quando nasce recebe de seu pai, Zeus, três presentes: uma mitra de ouro, uma lira e um carro puxado por cisnes.

${ }^{13}$ Observa-se que um dos motivos pode ser também porque Apolo por contraste com Deus cristão, não é um deus das primeiras gerações, nem um deus criador, cosmogónico.
} 
As montanhas altíssimas creadas, Montes, \& valles, arvores, \& frutos;

Potas as bellas fontes mateadas,

Que vão aos rios dando seus tributos:

Aves, peixes, serpentes fabricadas,

Os mansos animais, \& os ferós brutos. (Canto I, est.30, fl. 6)

Resgatado aqui com mais uma forma tradicional do mito, Apolo significa luz, que podemos interligar à ideia de luminosidade e transparência. Porém, como maneira de não engrandecer demasiado esta figura pagã, que lhe é inspiradora, Pimentel alude o livro de Gênesis e a estória da criação divina para mostrar que o Deus do cristianismo é tão mais luminoso que a própria luz do dia (ou seja, do que Apolo). Acima de tudo, esta é uma narrativa em que se contrapõe constantemente a luminosidade ao obscuro, por isso, Aurora, com sua luz, Phebea, Apolo, Flora e Pamona são representativos de símbolos cristãos de prosperidade e benefícios, enquanto Lúcifer, personificado como dragão, habita «região negra de Aqueronte», rio do infortúnio, localizado no mundo dos mortos, citando também o lago «Aveno», representativo do inferno. Ou seja, Pimentel retoma aqui a imagem de contemplador luminoso contida na segunda parte do Hino Homérico a Apolo que, como adita Paula Carreira, descreve um dos momentos mais destacados deste mito, justamente o que se refere à morte da serpente que atormentava e poluía as águas, e que teria por significado implícito:

\footnotetext{
Apesar de a sua luminosidade ser igualmente intrínseca, a morte de um monstro representa a morte da escuridão. Apolo como salvador daquele povo e purificador do local, traz uma nova vida, uma nova luz. Personifica a supremacia do racional sobre o irracional, o civilizado sobre o bárbaro, enfim, a luz sobre a escuridão. (CARREIRA, 2014, p. 93)
}

No segundo canto, mais uma vez há, dentre tantas outras passagens, uma tentativa de assimilação entre a mitologia clássica e a cultura cristã quando, por exemplo, Febo descobre as escrituras sagradas, justamente no reino de Tétis, a mãe de Aquiles:

Neste tempo Maria santa \& pura

O lavor dá almofada já deixava,

Porque Erebo trazia a noite escura,

E no reino de Thetis Phebo entrava:

Tomando o sacro livro da Escriptura,

Achou como Isaias declarava

Que huma Virgem a Deos conceberia,

E sempre intacta \& pura ficaria. (Canto II, est. 43, fl. 24v.)

Por ser representativo da luz, sendo associado à descoberta do divino, da claridade $\mathrm{e}$ clarividência, Apolo surge nesta passagem como o revelador de um futuro que glorificará a 
vinda da Virgem Maria, que é toda luz, quase que o equivalente de Apolo, e é retomada através da mulher salvadora descrita no «Apocalipse» (2000, 12: 1, p. 1601) palavras ditas por José, seu marido, no terceiro canto:

Porque lhe causa, Senhora, verdadeira,

Que vestida do sol, me enriquecestes,

E de meu norte estrella ser quisestes. (Canto III, est. 59, fl. 43)

Essa simbologia do sol como luz afortunada, ligada ao sentido nobre, é explicada por Maria Zambrano ao afirmar que «o sol divinizado traz consigo uma luz imperiosa, única, quase corporizada; é dominante e corresponde assim ao poder de um monarca absoluto que sempre se apresentou como seu filho» (ZAMBRANO, 1995, p. 41). Então, vestida de sol divino, Maria se torna, nesta epopeia, modelo de rainha, assumindo nesta narrativa épica características de uma heroína, visto Cristo ainda ser criança. Por isso, a solaridade cobre não apenas esta personagem, mas a própria narradora também se enriquece desta luz, desta sorte que lhe acompanha ao narrar esta epopeia, visto que «Le soleil, lui aussi, par count une carrière, dans les différentes étapes sont aisément assimilables à celles d'une vie éclarante: aurore, zénith, crepuscule. [...]. Comme le héros, le soleil entre dans l'ombre, et sort de l'ombre» (SELLIER, 1976, p. 17). Aliás, essa necessidade de realçar aspectos divinizados através de referências à luminosidade e seres luminosos, tendo Apolo como referência, faz Soror Pimentel recorrer à outra figura mitológica e de regência astrológica na passagem que refere o nascimento do menino Jesus:

\author{
E nove vezes trinta em seu dourado \\ Balcão se virão raios do sol fino, \\ E do Aries de ouro ao remontado \\ Capricornio enviou favor divino: \\ Despois que o mensageiro sublimado \\ Do soberano Rei, que he uno \& trino, \\ Se despedio de mim, \& logo unida \\ Ficou ao ser mortal a eterna vida. (Canto III, est. 65, fl. 44)
}

Dentre os diversos mitos de Memorial nos deparamos com a referência ao Velo de Ouro e a Capricórnio, numa alusão direta aos seres representados nas constelações, cujo ciclo do zodíaco ( 22 de dezembro a 20 de janeiro) integra a data fixada como nascimento de Cristo, 25 de dezembro, tendo esses seres o significado do «fogo-éter» da mitologia grega, sendo representativos de uma força criadora do mundo. Aliás, em outra passagem nos deparamos com mais uma referência à astrologia, justamente aquando do nascimento do menino Jesus, que segundo a narradora tem tantos laços com o Céu quanto a constelação de Gemini 
/Gémeos, que também representa, na mitologia grega, Castor e Pólux, irmãos de Helena de Troia:

Nem o Geminis tanto estreita os laços,

Nos ceos (se comparasse assi padião)

Como do filho aqui mudos braços. (Canto V, est. 25 , fl. 69 v.)

Também no Canto III, após algumas estrofes, ao apontar, mais uma vez, a pureza de Maria como dote divino, reaparece Febo Apolo como observador do norte triste:

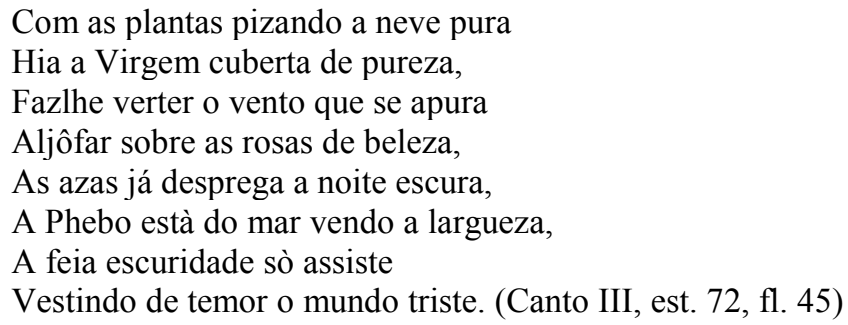

Febo, por ser luminosidade, assiste à escuridão triste da noite. Ou seja, ele é um observador do tempo e da mudança: do bem estar e vigorosidade, se contrapondo ao mal e ao obscuro. Isto fica evidente na passagem em que o anjo Gabriel, paraninfo de Deus, pede autorização ao «Padre eterno» para que os anjos possam ir à terra adorar aquela criança. Então, o esquadrão de anjos veste-se suntuosamente, com «mui ricas varias sedas», sendo representada quase como uma frota de Apolo e propositadamente associados a seres luminosos:

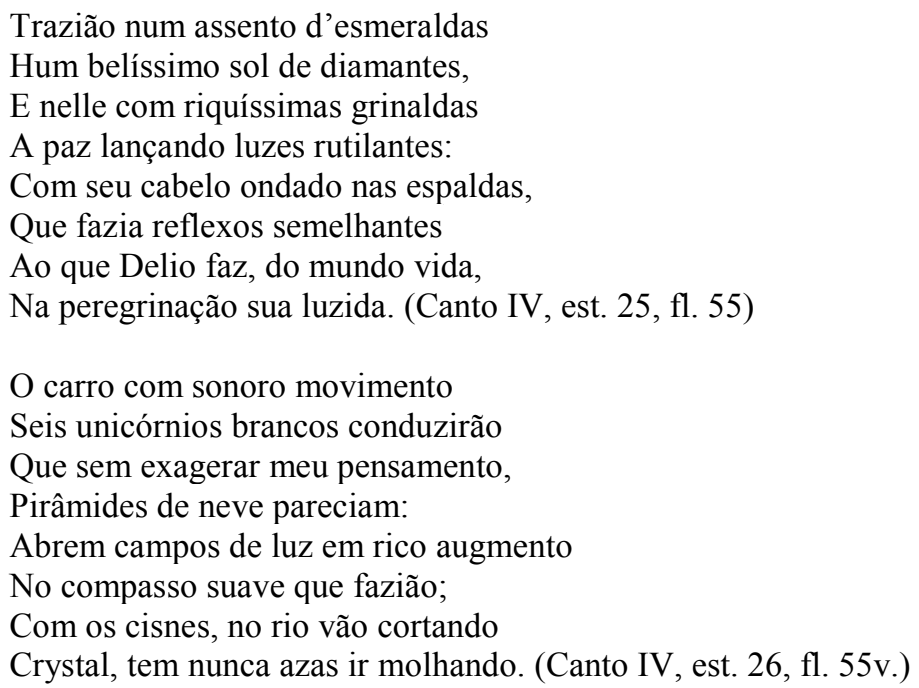

Veja-se que o Unicórnio (animal mitológico e, simultaneamente, do imaginário cristão) se junta aos cisnes apolíneos (que segundo a tradição seriam dois grandes brancos cisnes, presentes de Zeus, aquando do seu nascimento). Apesar de ser uma figura mitológica envolta em duplicidade, quer referente à castidade e inacessibilidade, quer ao desejo feminino, 
o unicórnio está enlaçado, na literatura dita fantástica e maravilhosa, a uma tradição medieval e renascentista com ligação à Virgem Maria (apesar de, efetivamente, isto não figurar na Bíblia): devido à concepção divina de Deus-Espírito Santo em Maria, entendida dentro do universo católico como dogma da virgindade perene desta - diferentemente da tradição protestante que assume o seu término com o parto do menino Jesus - esse animal se tornou um dos atributos recorrentes da Virgem. Isto tudo porque há uma tradicional leitura que apresenta o unicórnio como animal inacessível, bravo e feroz, capaz apenas de ser domado por uma virgem, assim como também dentro de especulações maniqueístas católicas. ${ }^{14}$

Uma outra passagem, no sexto canto, referindo-se ao carro de Délio, demonstra que os deuses estão ao serviço do propósito divino e, metaforicamente ou não, o carro de Apolo serve de ajuda à família sagrada aquando de sua fuga para o Egito:

O rico carro humilha Delio louro,

Para que o grão Joseph, \& casta esposa

Levando dentro nelle seu thesouro

Não lhe seja a jornada trabalhosa. (Canto VI, est. 106, fl. 97v.)

Apolo reaparece nesse mesmo canto ao lado de outra personagem mitológica, Prosérpina, passagem essa que serve de introdução à apresentação do menino Jesus no templo:

Dez vezes quatro Delio rubicundo,

Seguio vertendo luz, lua carreira,

E outras tantas com modo mui jucundo

Proserpina estendeo a cabelleira:

Quando aquelle Senhor, que fez o mûdo,

E a celestial maquina inteira,

Para que pontualmente a lei guardasse,

No templo quis q a mãi o apresentasse. (Canto VI, est. 56, fl. 89 v.)

A presença do mito de Prosérpina, aquela que traz luminosidade com a primavera e o verão, quando a natureza floresce, aquando de sua vinda do submundo, para onde foi raptada por Plutão, faz com que Apolo se associe às imagens primaveris, numa ligação imediata ao belo, tal como constatamos nesta passagem do Memorial...

Sete vezes em carro reluzente

Fez o fermoso Phebo Abril florido,

E por da alegria a toda a gente,

Lhe quis pôr esmeraldas no vestido. (Canto VIII, est. 78, fl. 125v.)

\footnotetext{
${ }^{14}$ Segundo Armand Strubel, esta dualidade acontece devido à seguinte dinâmica: «O mito literário do unicórnio elabora-se sobre esse fundo de erudição e de lenda. Tem data de nascimento exata. Na Bíblia faz menção do unicórnio poderoso e indomável, o Physiologus o incorpora a seu inventário de animais notáveis cuja aparência ou cujo comportamento remetem, pelos meandros da interpretação alegórica, à dominante tipológica e moral, às virtudes e vícios do cristão, ao Cristo e ao demônio, à História da Salvação» (STRUBEL, 1998, p. 919).
} 
Num dos últimos cantos há uma estrofe que fala do paraninfo do menino Jesus, um anjo capaz de roubar as luzes do sol e interceptar os raios de Apolo, ou seja, condensar em si mesmo todas as potencialidades da divinização, e que tem a função de anunciar à família sagrada o perigo que correm em Belém, visto que Herodes, instigado por figuras fantasmagóricas, é incitado a matar todos os primogénitos homens:

Quando do sacro assento, alto, \& divino

Descende hum Paranympho, que roubava

A luz do Ceo, que chamão crystallino.

E de Philesio os raios eclipsava:

Com seu subido voo peregrino

Das argentadas azas derramava

Grão copia de grão d'ouro \& de jacintos

Com divinos rubis todos distintos. (Canto VII, est. 14, fl. 100v.)

Apolo reaparece como observador, diante do massacre em Belém promovido pela ira de Herodes contra as crianças. O deus, juntamente com sua irmã Artemis (Délia), se sente atónito diante desse cenário sanguinolento:

De assombros se vestio o claro dia,

De sangue se mostrou Phebo manchado,

E morrendo de ver tal tyrania,

Em cinzas de crystal foi sepultado.

Com veo de escuro horror Delia sahia

Mostrando tambê rosto ensangoentado,

Porque abrazar a terra assi deseja,

Pois contra o alto Ceo feztal peleja. (Canto VIII, est. 28, fl.117)

Ou seja, recorre-se mais uma vez à mitologia grega demonstrando um apurado conhecimento de episódios e personagens do mundo clássico. Este resgate de Apolo está muito interligado à poesia de Pimentel, não apenas por ser um tipo de modismo na poesia portuguesa setecentista (na esteira, por exemplo, de Camões), mas por ter a sua natureza associada à pureza (apesar de algumas estórias tratarem Apolo como um deus cruel e impiedoso). Aliás, características essas aceites como preceito de vida de uma escritora que se consagrou como esposa de Cristo, aquando de seu encerramento no mosteiro de São Bento de Cástris, em Évora, sob aquilo que acreditava ser a verdade e integridade que devem acompanhar os Cristãos, e são qualidades encontradas no mito de Apolo, que representa «o deus da Luz, em que não existe a mínima mácula e, por isso, é também o Deus da Verdade nunca nenhuma palavra falsa brota dos seus lábios»(HAMILTON, 1942, p. 31).

Outro fato importante a notar é que se no período quinhentista, como refere Abel Pena, a referência a divindades pagãs pouco ou quase nada fere a consciência religiosa cristã, já que os deuses pagãos seriam vistos como uma componente ou recurso para se fazer poesia 
e fingimento literário: «os próprios ideais cristãos acabaram por validar e legitimar formas e termos pagãos já vazios no final do mundo antigo, criando uma espécie de "mitologia católica"»(PENA, 2008, p.39). O uso por Pimentel desses recursos é mais do que natural - e o que a autora faz com maestria, entendendo os limites e acepções que os deuses grecoromanos poderiam ou não ter em sua obra, devido à sua condição feminina. Como refere Isabel Morujão, ao constatar que a invocação a Nossa Senhora, a S. Bernardo e ao Espírito Santo, na obra de Pimentel, nega aclamação às Musas: «A Invocação apresenta, assim, nas entidades convocadas, a marca de uma prática e teoria poéticas próprias da Contra-Reforma, rejeitando as Musas tradicionais e substituindo-as por entidades de recorte histórico e natureza divina» (MORUJÃO, 2013, p. 162). Natureza divina e cristã essa, como observamos em Pimentel, presentes em Apolo, porque, como adita Pierre Grimal, o estudo em torno de Apolo pertence mais à história das religiões do que à mitologia, visto que ele «se tornou, pouco a pouco, o deus da religião órfica e que se ligou o seu nome a todo um sistema meio religioso meio moral, que prometia a salvação e a vida eterna aos seus iniciados» (GRIMAL, 2009, p. $34)$.

\section{Conclusão}

Em suma, a figura de Apolo comparece nesta epopeia com o propósito de cumprir uma função moral benéfica, e por isso cristã: legitima e auxilia a sua composição épica, perfazendo um senso comum setecentista na poesia; interliga-se à ideia de transparência e imaculidade, por ser luz inspiradora, cumprindo também a missão de assistente divino da família sagrada. Deixa-se saber também, numa das passagens citadas, que este deus se associa à descoberta e à aprendizagem quando se depara com as escrituras sagradas incutindo, assim, nesta figura mitológica, a sabedoria cristã, cristianizando-o. Apolo, ou mais propriamente o elemento luminoso que lhe está associado, é componente de criação do mundo e, construído também sob a égide da fartura, em torno do verão e da primavera, é, no âmbito astrológico, referência para a data fixada como nascimento de Cristo, remetendo para a produção de flores e frutos, num resgate de sua imagem primordial ligada à beleza. Este deus é um observador que perscruta ao longe, quando a noite/escuridão se apossa da solaridade, sendo também referida a sua consternação, devido à descrição trágica da matança dos primogénitos em Belém. Apolo é, então, apresentado por Pimentel dentro da dicotomia de componentes divinos e humanizados à disposição não apenas da poesia mas das coisas benéficas, as cristãs. Tudo o que vem de Apolo é abundante mas, no entanto, não tão glorioso quanto os preceitos católicos e cristãos. 
À Professora Doutora Vanda Anastácio ${ }^{15}$

\section{Referências}

ANASTÁCIO, Vanda; CASTRO, Inês de Ornellas e. O Banquete de Apolo: olhares cruzados sobre um papel da Restauração. In: ANASTÁCIO, Vanda; CASTRO, Inês de Ornellas e (Coord.). Revisitar os saberes. Referências clássicas na cultura portuguesa do renascimento à época moderna. Lisboa: Centro de Estudos Clássicos, 2010.

BÍBLIA SAGRADA. Tradução Euclides Martin Balancin e José Luís Gonzaga do Prado. 12.ed. São Paulo: Paulus, 2000.

BONNEFOY, Yves (Dir.). Dictionnaire des Mythologies et des religions des sociétés traditionnelles et du monde antique. Paris: Flammarion, 1981.

CARREIRA, Paula. As Argonáuticas de Apolónio de Rodes. A arquitectura de um poema helenístico. Prefácio Marília Pulquério Futre Pinheiro. Lisboa: Esfera do Caos, 2014.

GRAF, Fritz. Apollo. London and New York: Routledge, 2009.

GRIMAL, Pierre. Dicionário da Mitologia Grega e Romana. 5.ed. Lisboa: Difel, 2009.

HAMILTON, Edith. A Mitologia. Tradução Maria Luísa Pinheiro. Lisboa: Dom Quixote, 1942.

MORUJÃO, Isabel. Por Trás da Grade. Poesia Conventual Feminina em Portugal (Séculos XVI-XVII). Lisboa: Imprensa Nacional-Casa da Moeda, 2013.

PENA, Abel N. Mito de Apolo. In: SILVA, Vítor Aguiar e (Coord.). Dicionário de Luís de Camões. Lisboa: Caminho, 2010. p. 31-33.

PENA, Abel N. Apolo e as Musas na mitografia dos poetas quinhentistas. In.: PENA, Abel N., Mythos. Actas do Colóquio Internacional A Tradição mitográfica portuguesa. Representação e Identidade. Séculos XVI-XVIII. Lisboa: Centro de Estudos Clássicos, 2008. p. 37-53.

PIMENTEL, Soror Maria de Mesquita. Memorial da Infancia de Christo e Triumpho do divino Amor (primeira parte). Lisboa: Jorge Rodriguez, 1639.

SELLIER, Philippe. Le mythe du héros. Bordas/ Nancy: Univers des lettres Bordas, 1976.

STRUBEL, Armand. O Unicórnio. In: BRUNEL, Pierre (Org.). Dicionário de Mitos Literários. Tradução Carlos Sussekind. Prefácio à edição brasileira de Nicolau Sevcenko. 2. ed. Rio de Janeiro: Olympio, 1998. p. 918-922.

ZAMBRANO, María. O homem e o divino. Tradução Cristina Rodriguez e Artur Guerra. Lisboa: Relógio d'Água, 1995.

\footnotetext{
${ }^{15} \mathrm{O}$ acolhimento com que recebeu o meu trabalho e me incentiva nas minhas pesquisas equivalem à dedicação enquanto professora e co-supervisora do meu projeto de pós-doutoramento sempre empenhada no desenvolvimento das pesquisas e incentivo aos seus alunos.
} 
[Recebido em agosto de 2014 e aceito para publicação em março de 2015]

Phoebus Apollo in the epic plot in the Memorial of the Christ's Childhood and Triumph of the divine Love (1639) by Soror Maria de Mesquita Pimentel

Abstract: This article focuses on how it is represented the figure of Apollo in the religious epic by Soror Maria de Mesquita Pimentel (1581-1661) that had taken her vows at the Monastery of Saint Benedict of Cástris in the city of Évora as a nun of the Cistercian Order. She became a pionery because written and published the first epic work by a woman in Portuguese language: Memorial da Infância de Christo e Triumpho do Divino Amor (1639). This book is a key work for our understanding of both gender and epic studies, both in the context of Portuguese literature and from the standpoint the greek mythology including in the monasteries. For this we will make a survey around what the critics say about this god and which are the appropriations that the writer-nun gives to this myth in her text because he figures quite often, more than other mythological gods, with clearly intended to demonstrate the symbolic plurality of this deity in the service of what is benevolent and Christian.

Keywords: Apollo. Mythology. Religion Epic. Soror Maria de Mesquita Pimentel

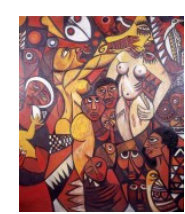

